\title{
UNA NUEVA ESPECIE DE EUGENIA L. (MYRTACEAE) DE LAS SELVAS HÚMEDAS COSTARRICENSES
}

\author{
PABLO E. SÁNCHEZ-VINDAS \\ Herbario Juvenal Valerio Rodríguez, Universidad Nacional, apdo. 86-3000, Heredia, Costa Rica. \\ pesanche@una.ac.cr
}

\begin{abstract}
A new species of Eugenia (Myrtaceae) from the Caribbean of Costa Rica is described. It is easy to distinguish by its leaves with double marginal nerves and by its fruits which are ribbed and very reticulate.
\end{abstract}

Resumen. Se describe una nueva especie de Eugenia (Myrtaceae) de la vertiente caribe de Costa Rica. Se distingue por las hojas con doble nervio marginal y los frutos acostillados y muy reticulados.

Palabras Clave / Key words: Myrtaceae, Eugenia earthiana, Costa Rica

Eugenia es un género con más de 2000 especies distribuidas en las zonas tropicales y subtropicales del Nuevo y del Viejo Mundo, siendo América uno de los centros de mayor diversidad (Sánchez 1990); probablemente en Costa Rica se encuentren más de 35 especies.

Como parte de la exploración botánica que realiza el personal del Herbario Juvenal Valerio Rodríguez (JVR) en el caribe costarricense, en busca de plantas con potencial insecticida, hemos recolectado una nueva especie para la ciencia, que me permito describir a continuación.

\section{Eugenia earthiana P.E. Sánchez, sp. nova}

TIPO: Costa Rica. Limón: Guácimo; Reserva Forestal de la Escuela de Agricultura de la Región Tropical Húmeda (EARTH), Sendero Escalera de Mono, 50 m, 6 abr 2002 (fl, fr), P. E. Sánchez, L. J. Poveda \& C. Sandi 2035 (holotipo: CR, isotipos: F, MO, NY, US).

Fотоs 1, 2, 3.

Arbor usque ad $5 \mathrm{~m}$ alta, ramulis teretibus, foliis oblongis ellipticis, $6-9.8 \mathrm{~cm}$ longis, $1.9-3.5 \mathrm{~cm}$ latis, apice acuminato; petiolo puberulo, 2-3 mm longo; inflorescentia axillari, dense porphyreo-tomentosa, floribus 2-5; fructo oblato, conspicue costato-reticulato, 1-2 cm longo, semine uno per fructum.

Árbol pequeño, hasta de $5 \mathrm{~m}$ de altura; corteza externa parda y lisa, la interna rosada; ramitas cilín- dricas, con denso tomento pardo-rojizo; ramitas viejas cilíndricas, pardo-claras o grisáceas, puberulentas, con corteza levemente fisurada; tricomas simples de ca. $0.5 \mathrm{~mm}$ de largo. Hojas de $6.0-9.8 \mathrm{~cm}$ de largo y 1.9-3.5 cm de ancho; pecíolos cilíndricos, engrosados, con denso tomento pardo-rojizo, de $2-3 \mathrm{~mm}$ de largo y ca. $1.5 \mathrm{~mm}$ de ancho. Lámina foliar membranácea, con numerosos puntos glandulosos negruzcos, visibles principalmente por el envés, cuando seca verde oscura y opaca en la haz, verde oliva en el envés, oblonga a oblongo-elíptica, ápice acuminado, a veces algo falcado-acuminado, base redondeada, algunas veces levemente subcordada, los lóbulos redondeados; el margen en material fresco ondulado; nervio central glabro y profundamente inmerso en la haz, muy prominente y pardo-rojizo tomentoso en el envés, nervios laterales 13-18 pares incluyendo algunos intermedios, orientados $38^{\circ}-40^{\circ}$ con relación al nervio central en la parte media de la lámina, glabros e inmersos en la haz, glabros o esparcidamente pubescentes y prominentes en el envés, nervios terciarios muy reticulados, glabros y conspicuos en ambas superficies, los nervios laterales anastomosados, formando un nervio marginal muy prominente en el envés, glabro en ambas superficies, 3-4 mm del margen, a partir del nervio marginal los nervios terciarios anastomosados formando un nervio submarginal a $1 \mathrm{~mm}$ del margen. Inflorescencia un racimo o fascículo, 2-5 flores, raro solitarias, 1-2 por axila, densamente pardo-rojizo tomentosa; pedúnculo cilín- 


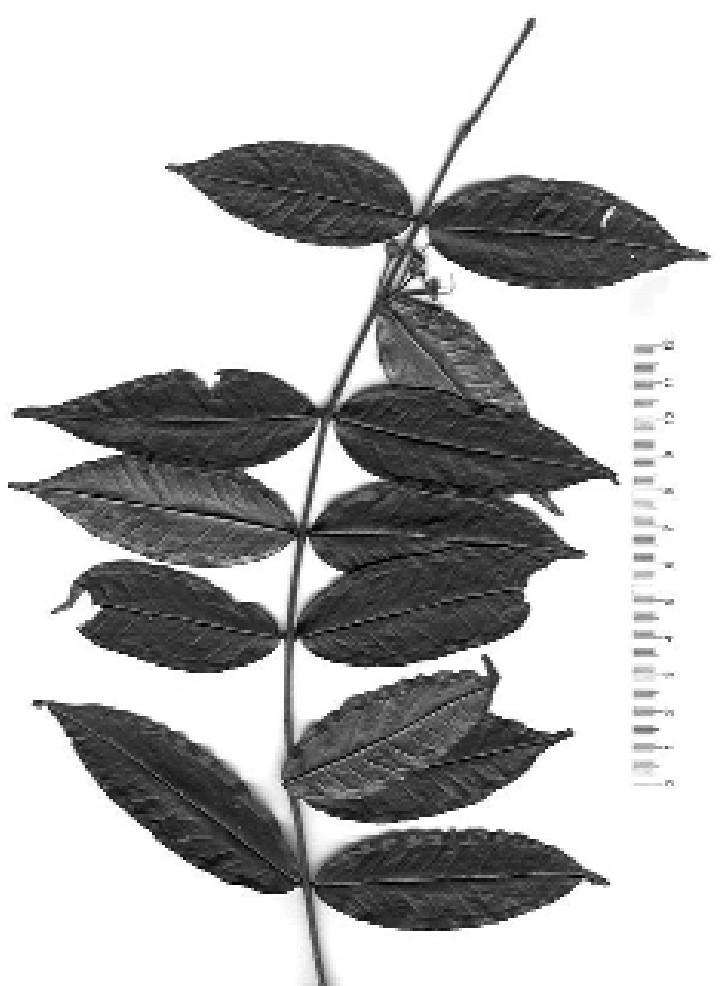

Foto 1. Eugenia earthiana P.E. Sánchez. Ramita fértil. P.E. Sánchez et al. 2035 (CR).

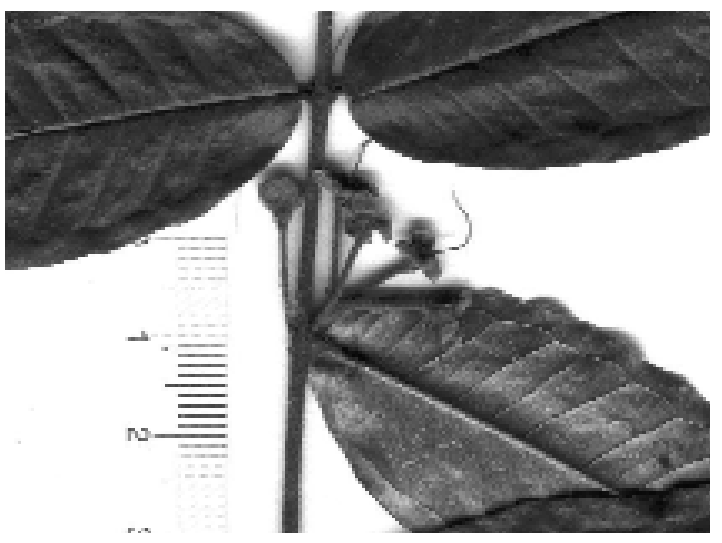

Foto 2. Eugenia earthiana P.E. Sánchez. Detalle de una inflorescencia. P. E. Sánchez et al. 2035 (CR).

drico, densamente pardo-rojizo tomentoso, $0.5-4 \mathrm{~mm}$ de largo; brácteas cóncavo-deltoides, densamente pardo-rojizo tomentosas, $c a$. $1 \mathrm{~mm}$; pedicelos cilíndricos, densamente pardo-rojizo tomentosos, 8-15 $\mathrm{mm}$ de largo; bracteolas 2, libres, deltoides, densamente pardo-rojizo tomentosas abaxialmente, glabras

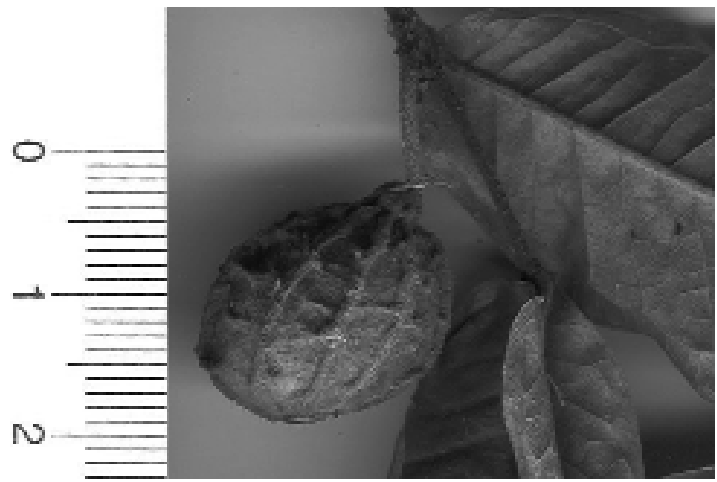

Foto 3. Eugenia earthiana P.E. Sánchez. Detalle del fruto. P.E. Sánchez et al. 2035 (CR).

internamente, glanduloso-punteadas, 1-1.5 mm de largo; yemas florales globosas, densamente pardorojizo tomentosas, $c a .4 \mathrm{~mm}$ de largo; hipanto en forma de copa, densamente pardo-rojizo tomentoso, ca. $2 \mathrm{~mm}$ de largo; lóbulos del cáliz 4, cóncavoredondeados, densamente pardo-rojizo tomentosos abaxial e internamente, glanduloso-punteados, $c a$. 3.5 $\mathrm{mm}$ de largo, ca. $3 \mathrm{~mm}$ de ancho; disco estaminal redondeado, pardo-rojizo tomentoso, $c a .4 \mathrm{~mm}$ de largo; cicatrices de los estambres 90-120; ovario bilocular; óvulos 8-13 en cada lóculo; estilo glabro, ca. $10 \mathrm{~mm}$ de largo. Frutos redondeados u oblatos, pardos o pardo-amarillentos cuando secos, en material vivo verde amarillentos, tornándose anaranjados con manchas amarillentas o púrpuras al madurar, 1-2 $\mathrm{cm}$ de largo y $2-2.5 \mathrm{~cm}$ de ancho, diminutamente pubescentes y evidentemente acostillados y reticulados, densamente glandulosos, coronados en el ápice con los lóbulos del cáliz; pedúnculo de $c a .4 \mathrm{~mm}$ de largo; semilla 1, con el embrión homogéneo, con los cotiledones y la radícula no discernibles.

Paratipos. AlaJUela: Cantón de San Carlos; cuenca del San Carlos, ca. $7 \mathrm{~km}$ NE de Boca Tapada, Lagarto Lodge, $10^{\circ} 41^{\prime} 10^{\prime \prime} \mathrm{N}, 84^{\circ} 10^{\prime} 50^{\prime \prime} \mathrm{W}, 90 \mathrm{~m}, 27$ jul 1996 (fr.), B. Hammel 20346 (INB, MO). HEREDIA: Cantón de Sarapiquí; Llanura de San Carlos, La Virgen, $10^{\circ} 24^{\prime} 35^{\prime} \mathrm{N}$, $83^{\circ} 54^{\prime} 00^{\prime \prime} \mathrm{W}, 220 \mathrm{~m}, 18$ oct 1996 (fr), N. Zamora, D. Delgado \& V. Herra 2526 (INB, MO). LIMÓN: Cordillera de Talamanca, entre la Quebrada Camagre y Río Barbilla, 180-480 m, sept 1988 (fr.), M. Grayum, G. Herrera et al. 8938 (CR, MO); Talamanca, Suretka, 200 m, abr 1982 (fr.), Gómez-Laurito 8354 (CR); Siquirres, Finca de don J. Berrocal, 60-70 m, nov 1986 (fr.), N. Zamora, M. Grayum \& J. Berrocal 1302 (CR). 
DISTRIBUCIÓN Y HÁBITAT. Esta especie es hasta ahora endémica en Costa Rica, distribuida solamente en el Caribe. Crece asociada con Carapa guianensis Aubl., Pentaclethra macroloba (Willd.) Kuntze, Simarouba amara Aubl., Welfia regia Mast., Quararibea cordata (Bonpl.) Vischer, Ryania speciosa Vahl, Protium ssp., entre otras. Sus flores han sido observadas de abril a mayo y los frutos entre septiembre y abril.

ETIMOLOGÍA. El epíteto de la especie está dedicado a la Escuela de Agricultura de la Región Tropical Húmeda (EARTH), donde es una especie relativamente abundante en el área boscosa protegida por este centro de enseñanza e investigación.

\section{CARACTERÍSTICAS DIAGNÓSTICAS. Eugenia earthiana} es fácil de distinguir de las demás especies de Eugenia, por su nervios muy prominentes en el envés, los nervios marginal y submarginal muy evidentes y, sobretodo, por sus ramitas, pecíolos e inflorescencias densamente pardo-rojizo tomentosos y sus frutos evi- dentemente acostillado-reticulados. Por los frutos está relacionada con E. matagalpensis P.E. Sánchez, que se distribuye en las nebliselvas de Nicaragua y Costa Rica, pero difiere por su distribución altitudinal (1300-1700 m), por poseer hojas usualmente de menos de $6 \mathrm{~cm}$ de largo y flores con pedicelos de 2-3 mm de largo (Sánchez 2001).

AgradeCimientos. Al amigo Carlos Sandí, incansable trabajador de la EARTH, quien siempre me colaboró con las observaciones fenológicas de la especie; a Fred Barrie del Field Museum of Natural History por la revisión del texto y las sugerencias.

\section{LITERATURA CITADA}

Sánchez, P.E. 1990. Myrtaceae. In: A. Gómez-Pompa (ed.). Flora de Veracruz 62: 1-146. México, Instituto de Ecología / Univ. of California.

Sánchez, P.E. 2001. Eugenia L. In: Stevens, W.D. et al. (eds.). Flora de Nicaragua 2(85): 1570-1574. Missouri Botanical Garden. 